\title{
Comparison between dexmedetomidine and propofol on outcomes after coronary artery bypass graft surgery: a retrospective study
}

Jie Hu${ }^{1 *}$, Bingfeng Lv' ${ }^{1}$, Raha West ${ }^{2}$, Xingpeng Chen ${ }^{3}$, Yali Yan ${ }^{4}$, Chen Pac Soo ${ }^{2,5}$ and Daqing $\mathrm{Ma}^{2 *}$

\begin{abstract}
Background: Dexmedetomidine (DEX) has a pharmacological profile that should allow rapid recovery and prevent undesirable outcomes such as pulmonary complications.

Methods: This large retrospective study compared the beneficial effects of perioperative infusion of DEX with propofol on the postoperative outcome after coronary artery bypass graft surgery. We reviewed patients' medical notes at Luoyang Central Hospital from 1st January 2012 to 31st December 2019. All continuous variables, if normally distributed, were presented as mean \pm SD; Otherwise, the non-normally distributed data and categorical data were presented as median (25-75 IQR) or number (percentage). The Mann-Whitney $U$ test and Chi-square test were used to evaluate the difference of variables between the DEX and propofol groups. Multivariate logistic regression analysis was performed on the main related and differential factors in the perioperative period.

Results: A total of 1388 patients were included in the study; of those, 557 patients received propofol infusion, and 831 patients received dexmedetomidine. DEX significantly reduced postoperative pulmonary complications compared with propofol, $7.82 \%$ vs $13.29 \% ; P<0.01$, respectively. When compared with propofol, DEX significantly shortened the duration of mechanical lung ventilation, $18(13,25)$ hours vs $21(16,37)$ hours; $P<0.001$, the length of stay in the intensive care unit, $51(42,90)$ vs $59(46,94.5)$ hours; $P=0.001$ and hospital stay, $20(17,24)$ vs $22(17,28)$ days; $P<0.001$, respectively. The incidences of postoperative wound dehiscence and infection were significantly reduced with DEX compared with propofol groups, $2.53 \%$ vs 6.64\%; $P<0.001$, respectively. Interestingly, patients receiving DEX had significantly shorter surgical time compared to propofol; $275(240,310)$ vs $280(250,320)$ minutes respectively $(P=0.005)$ and less estimated blood loss $(P=0.001)$.
\end{abstract}

Conclusion: Perioperative infusion of dexmedetomidine improved the desirable outcomes in patients who had coronary artery bypass graft surgery compared with propofol.

Keywords: Dexmedetomidine, Propofol, CABG, Pulmonary complications, Surgical time

*Correspondence: hujielyzxyy@163.com; d.ma@imperial.ac.uk

${ }^{1}$ Department of Anesthesiology, Luoyang Central Hospital Affiliated

to Zhengzhou University, Luoyang, Henan, China

${ }^{2}$ Division of Anaesthetics, Pain Medicine and Intensive Care, Department

of Surgery and Cancer, Faculty of Medicine, Imperial College London,

Chelsea and Westminster Hospital, London, UK

Full list of author information is available at the end of the article

\begin{abstract}
Introduction
The optimum intraoperative anaesthetic agent for cardiac surgery should allow the patients to recover rapidly and prevent undesirable outcomes such as pulmonary complications, prolonged mechanical lung ventilation, and prolonged stay in the intensive care unit (ICU). Prolonged mechanical ventilation and ICU stay are associated with high morbidity and mortality rates following cardiac surgery $[1,2]$. Anaesthetic techniques and agents
\end{abstract}

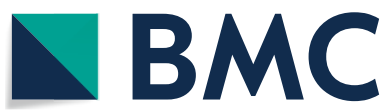

(c) The Author(s) 2022. Open Access This article is licensed under a Creative Commons Attribution 4.0 International License, which permits use, sharing, adaptation, distribution and reproduction in any medium or format, as long as you give appropriate credit to the original author(s) and the source, provide a link to the Creative Commons licence, and indicate if changes were made. The images or other third party material in this article are included in the article's Creative Commons licence, unless indicated otherwise in a credit line to the material. If material is not included in the article's Creative Commons licence and your intended use is not permitted by statutory regulation or exceeds the permitted use, you will need to obtain permission directly from the copyright holder. To view a copy of this licence, visit http://creativecommons.org/licenses/by/4.0/. The Creative Commons Public Domain Dedication waiver (http://creativeco mmons.org/publicdomain/zero/1.0/) applies to the data made available in this article, unless otherwise stated in a credit line to the data. 
used during surgery to accelerate weaning from mechanical lung ventilation and patient's recovery are essential for fast-track cardiac anaesthesia and are increasingly being adopted.

Dexmedetomidine (DEX) is a highly selective shortacting $\alpha_{2}$-adrenoceptor agonist with properties including sedative, analgesic, anxiolytic, opioid and anaesthetic sparing effects [3]. DEX has minimal impact on respiratory depression, improves oxygenation and lung compliance, and reduces postoperative pulmonary complications $[4,5]$. DEX also alleviates perioperative stress, inflammatory and immune response leading to an excellent postoperative recovery [6]. Perioperative use of DEX as an anaesthetic adjunct and postoperative sedation was reported to reduce the time spent on mechanical ventilation, improve 30 days mortality, shorten ICU and hospital stay, and decrease postoperative complications, including the incidence of pulmonary complications and delirium and acute kidney injury $[7,8]$.

Several studies demonstrated the benefit of DEX infusion in providing haemodynamic stability during cardiac surgery [9-11]. Meta-analysis studies on the use of DEX during cardiac surgery also showed a reduction in the risk of atrial fibrillation, ventricular tachycardia and cardiac arrest $[7,12]$. The potential impact of the haemodynamic stability provided by DEX during cardiac surgery on intraoperative outcomes is still limited.

In this study, we analysed our patients' data retrospectively. We investigated the potential benefits of DEX compared to propofol during and after anesthesia and surgery on postoperative outcomes in patients undergoing coronary artery bypass graft surgery (CABG). We also explored the potential benefits of DEX infusion during surgery on intraoperative outcomes such as blood loss, blood transfusion, duration of anaesthetic and surgery, and opiates consumption in those patients.

\section{Methods}

\section{Study design and setting}

This retrospective cohort study was approved by the Ethics committee of Luoyang Central Hospital, Zhengzhou University, Henan, China. Because of its retrospective study nature, the need for informed consent was waived. All methods were performed following the relevant guidelines and regulations. The manuscript was prepared according to the statement on the Strengthening the Reporting of Observational Studies in Epidemiology (STROBE) [13].

\section{Participants}

The inclusion criteria were patients aged 18 and above who received either DEX or propofol infusion during CABG surgery as an adjunct for general anaesthesia and as a postoperative sedative drug until extubation in the ICU. Exclusion criteria were patients receiving DEX and propofol together at any time during the intraoperative and postoperative periods except for an induction dose of propofol at the start of general anaesthesia and patients who had severe comorbidities, including valvular heart disease, infections, and lung, kidney and liver dysfunction.

\section{Perioperative management}

After the patients had received premedication of $10 \mathrm{mg}$ morphine and $0.3 \mathrm{mg}$ scopolamine by intramuscular injection, they were anesthetised with etomidate $(0.3 \mathrm{mg} /$ $\mathrm{kg})$, sufentanil $(0.8 \mu \mathrm{g} / \mathrm{kg})$ and atracurium $(0.2 \mathrm{mg} /$ $\mathrm{kg}$ ), their tracheas were intubated, and their lungs were mechanically ventilated $(\mathrm{I} / \mathrm{E}=1: 1.5 ; \quad \mathrm{VT}=6-8 \mathrm{ml} / \mathrm{kg}$; $10-12 / \mathrm{min})$. Anesthesia was maintained with infusions of propofol or DEX initially at $2-12 \mathrm{mg} / \mathrm{kg} / \mathrm{hr}$. or $1.0 \mu \mathrm{g} / \mathrm{kg} /$ hr., respectively, and reduced thereafter to DEX $0.3 \mu \mathrm{g} /$ $\mathrm{kg} / \mathrm{hr}$. All patients received 1-2\% sevoflurane, sufentanil $(0.6-0.8 \mu \mathrm{g} / \mathrm{kg})$ and atracurium $(0.1 \mathrm{mg} / \mathrm{kg})$ when required during surgery. Patients received routine monitoring, including invasive arterial pressure, Bispectral Index (BIS) (Covidien, USA) value, body temperature, pulse oximetry and ECG. Pulmonary artery pressure, cardiac index and cardiac output were continuously monitored via a Swan-Ganz catheter (Vigileo II, Edwards, Irvine, USA).

The patients underwent median sternotomy; the left internal mammary artery and part of the saphenous vein were harvested at normal body temperature. Heparin was administered intravenously to adjust the activated clotting time readings within the appropriate range. CABG was performed on a beating heart with off-pump surgery as a routine procedure. However, if the mean pulmonary artery pressure was higher than $50 \%$ of the mean arterial pressure and the patient was haemodynamically unstable when surgeons attempted to elevate the heart for surgery, a heart beating on-pump surgery was performed using partial assistance from the cardiopulmonary bypass $(\mathrm{CPB})$. The patient was connected to the $\mathrm{CPB}$ circuit to maintain circulation, and the coronary artery bypass grafting was completed under $\mathrm{CPB}$ assistance without cardiac arrest. Methoxamine was used to increase peripheral vascular resistance when raising the patient's heart during off-pump CABG, with volume control to maintain circulatory stability and reduce myocardial oxygen consumption. Because it is necessary to control the patient's heart rate during off-pump CABG, only methoxamine was used without other positive inotropic drugs, for example, norepinephrine, which could excite the $\beta$ receptor. 


\section{Outcomes}

The primary outcome measured was pulmonary complication following CABG between patients who received DEX or propofol. This was defined as any pre-defined pulmonary complications following surgery, including respiratory infection, respiratory failure, pleural effusion, atelectasis, pneumothorax, bronchospasm, aspiration pneumonitis, pulmonary oedema, pulmonary embolism, and acute respiratory distress syndrome.

The secondary outcomes include the duration of mechanical lung ventilation, postoperative morbidity, 30-day mortality and length of stay (LOS) in ICU and hospital. We also looked at exploratory outcomes of intraoperative findings such as surgical times and estimated blood loss.

\section{Data collection}

Demographic data such as age, gender, body mass index, comorbidities including cardiac arrhythmia type and alcohol consumption (alcoholism: defined as drinking wine during two meals/day), American Society of Anaesthesiology (ASA) physical status classification and laboratory data of kidney function, blood count and $\mathrm{C}$-reactive protein (CRP) were collected. Intraoperative data included inotropic drugs used, anaesthetic agents, duration of anaesthesia, duration of surgery, intraoperative fluid, urine output, autologous blood transfusion, extracorporeal circulation and intra-aortic balloon pump assistance.

Postoperative data including new-onset cardiac arrhythmia and complications after surgery were also collected as outcome measures. Postoperative pulmonary complications were defined as postoperative pneumonia, hypoxemia $\left(\mathrm{PaO}_{2} / \mathrm{FiO}_{2} \leq 300 \mathrm{mmHg}\right)$, postoperative respiratory failure $\left(\mathrm{PaO}_{2} / \mathrm{FiO}_{2} \leq 200 \mathrm{mmHg}\right.$ and required mechanical ventilation for more than $48 \mathrm{~h}$ ) and atelectasis and bronchospasm exacerbation of pre-existing chronic lung disease. Surgical bleeding was defined as chest tube drainage exceeding $500 \mathrm{ml}$ per hour or $200 \mathrm{ml}$ per hour for three consecutive hours accompanied by blood volume replacement and hemodynamic instability.

\section{Statistical analysis}

All continuous variables, if normally distributed, were presented as mean $\pm \mathrm{SD}$; otherwise, the non-normally distributed data and categorical data were presented as median (25-75 IQR) or number (percentage). First, we compared the clinical characteristics, including demographic data, laboratory data, post-operative data and data during surgery. The Mann-Whitney U test was used to analyze continuous variables. The Chisquare test was used to compare categorical variables to evaluate the difference between the DEX and the propofol group. Based on the statistical comparisons between the two groups, the significant preoperative factors and important perioperative factors related to the postoperative pulmonary complications such as time of surgery, length of stay in the hospital, duration of mechanical ventilation, length of stay in ICU after surgery, DEX use, CPB assistance, diabetes, wound infection, age and BMI were integrated into a multivariate logistic regression model, and the adjusted ORs, 95\% CIs, and P values were calculated for each variable. All data were analysed with SPSS 22 (ABS, USA). A P value less than 0.05 was considered to be of statistical significance.

\section{Results \\ Baseline patient demographic and perioperative characteristics}

Routinely collected data were captured by the direct care team for patients undergoing CABG at Luoyang Central Hospital from 1st of January 2012 to 31st of December 2019. A total of 1503 patients had CABG during the studied period being carried out by the same team of surgeons and anesthesiologists; 115 of them were excluded based on our exclusion criteria. Data for the study were from the remaining 1388 patients (Fig. 1). Of those, 831 patients received DEX, and 557 received propofol as an anaesthetic adjunct during surgery and postoperative sedation. There were no significant differences between the two groups in terms of age, gender, body mass index, blood type, ASA classification and comorbidities, including stroke, chronic obstructive pulmonary disease, diabetes, hyperlipidaemia, smoking, liver dysfunction, chronic kidney disease and chronic heart failure (Table 1). There were more patients with cardiac arrhythmia comorbidity $(6.64 \%$ vs $3.37 \%, P=0.005)$ and alcoholism $(29.44 \%$ vs $19.98 \%, P<0.001)$ in the propofol compared to the DEX group. Before surgery, there were no differences in kidney function, white blood cells, and neutrophils between the two groups. However, all measurements were significantly raised after surgery in the propofol group compared to DEX (Table 2).

\section{Primary outcomes}

Perioperative DEX significantly reduced pulmonary complications collectively, including hypoxemia, atelectasis, pneumonia, bronchospasm, and pleural effusion, with $7.82 \%$ total complications in the DEX compared to $13.29 \%$ in the propofol group $(P<0.01)$. When broken down into the individual pulmonary complication, although the general trend, except for pleural effusion, pointed towards a better pulmonary outcome for the 


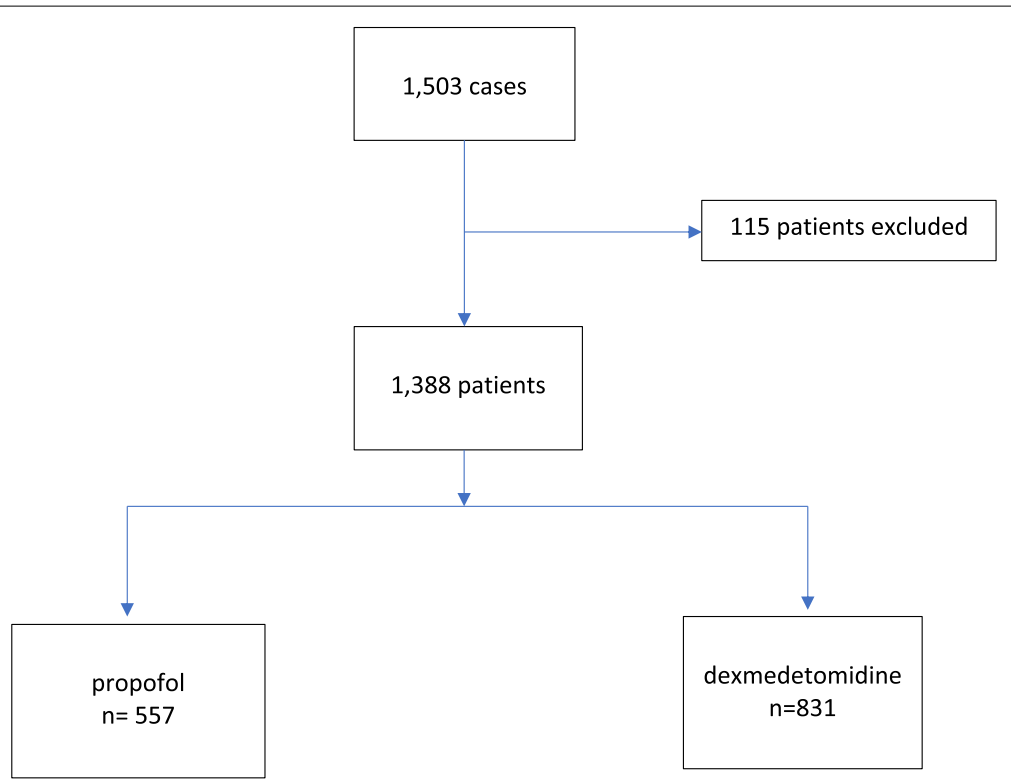

Fig. 1 Flow chart of patients included for data analysis

DEX group, only atelectasis was statistically different with $1.32 \%$ incidence in the DEX compared to $2.87 \%$ in propofol $(P=0.048)$ (Table 3$)$.

Looking at important perioperative factors that could influence postoperative pulmonary complications, DEX (OR 0.544, $P=0.002)$ and $\mathrm{CPB}(0.140, P<0.001)$ were associated with a decrease in postoperative lung complications but diabetes (OR 1.500, $P=0.040)$ and wound infection (OR 3.995, $P<0.001)$ increased the risk of lung complications (Table 4). Preoperative cardiac arrhythmia and alcoholism, which were significantly more common in the propofol group than DEX, did not significantly worsen postoperative pulmonary complications following multivariate logistic regression analysis, OR 0.709, $P=0.548$ and OR $0.975, P=0.913$ respectively.

\section{Secondary outcomes}

For the secondary outcomes, perioperative DEX infusion was associated with a significant reduction in mechanical lung ventilation duration, LOS in ICU after surgery and LOS in hospital. The mean time to extubation was $18(13,25)$ hours in the DEX vs $21(16,37)$ hours in the propofol group $(P<0.001)$. LOS in ICU following surgery was $51(42,90)$ hours with DEX compared to $59(46,94.5)$ hours in the propofol group $(P=0.001)$. The length of hospital stay was also shorter with DEX compared to the propofol group with $20(17,24)$ vs $22(17,28)$ days, respectively $(P<0.001)$ (Table 3$)$.

The incidence of postoperative wound dehiscence or infection was also significantly lower in the DEX group than propofol; $2.53 \%$ vs $6.64 \%$, respectively $(P<0.001)$.
There were no significant differences in the 30 days mortality, postoperative complications such as arrhythmias, acute kidney injury, stroke or upper gastrointestinal bleeding (Table 3). Cardiac ejection fraction and C-reactive protein showed no statistical significance between the two groups before and after surgery (Fig. 2).

\section{Exploratory outcomes}

Patients receiving DEX had a slightly shorter surgical time than propofol. Patients in the DEX group required fewer opioids (sufentanil) and inotropic drugs than those in the propofol group $(P=0.001)$. There was no significant difference in the two groups concerning the intraoperative fluid administration, urine output, autologous blood transfusion, extracorporeal circulation, and the use of an intra-aortic balloon pump (Table 5).

\section{Discussion}

In this large retrospective study of 1388 patients, the perioperative use of DEX shows an overall reduction in postoperative pulmonary complications, duration of mechanical lung ventilation, wound dehiscence or infection, length of ICU and hospital stay. Hypoxemia, atelectasis, pneumonia and bronchospasm are common in patients after cardiac surgery. In this study, these postoperative pulmonary complications tend to be less in the DEX group than in the propofol group, but only atelectasis was statistically significant. Atelectasis could be significantly less in the DEX group due to the reduction of lung inflammation, sputum stasis, and the association 
Table 1 Demographic data

\begin{tabular}{|c|c|c|c|}
\hline & Propofol $(n=557)$ & Dexmedetomidine $(n=831)$ & $P$ value \\
\hline Age & $62(56,68)$ & $63(57,68)$ & 0.515 \\
\hline Gender (male/female) & $422 / 135$ & $615 / 216$ & 0.461 \\
\hline $\mathrm{BMI}\left(\mathrm{kg} / \mathrm{m}^{2}\right)$ & $24.91(23.29,26.08)$ & $24.61(22.76,26.45)$ & 0.184 \\
\hline \multicolumn{4}{|l|}{ Blood type } \\
\hline A & $143(26.67 \%)$ & $217(26.11 \%)$ & \multirow[t]{4}{*}{0.493} \\
\hline B & $179(32.14 \%)$ & $267(32.13 \%)$ & \\
\hline $\mathrm{O}$ & $182(32.67 \%)$ & $249(29.97 \%)$ & \\
\hline$A B$ & $53(9.52 \%)$ & $98(11.79 \%)$ & \\
\hline \multicolumn{4}{|l|}{ Co-comorbidity } \\
\hline Cardiac arrhythmia & $37(6.64 \%)$ & $28(3.37 \%)$ & 0.005 \\
\hline Sinus tachycardia & 6 & 4 & 0.198 \\
\hline Sinus bradycardia & 5 & 4 & 0.344 \\
\hline Atrial fibrillation & 15 & 10 & 0.041 \\
\hline Atrial premature beats & 7 & 6 & 0.369 \\
\hline Atrioventricular block & 4 & 4 & 0.721 \\
\hline Stroke & $101(18.13 \%)$ & $122(14.68 \%)$ & 0.086 \\
\hline COPD & $10(1.79 \%)$ & $21(2.53 \%)$ & 0.366 \\
\hline Diabetes & $167(29.98 \%)$ & $236(28.4 \%)$ & 0.524 \\
\hline Hyperlipidemia & $146(26.21 \%)$ & $209(25.15 \%)$ & 0.657 \\
\hline Smoke & $251(45.06 \%)$ & $387(46.57 \%)$ & 0.581 \\
\hline Alcoholism & $164(29.44 \%)$ & $166(19.98 \%)$ & $<0.001$ \\
\hline Liver dysfunction & $9(1.62 \%)$ & $11(1.32 \%)$ & 0.654 \\
\hline Chronic kidney disease & $8(1.44 \%)$ & $12(1.44 \%)$ & 0.990 \\
\hline Chronic heart failure & $53(9.52 \%)$ & $58(6.98 \%)$ & 0.088 \\
\hline \multicolumn{4}{|l|}{ ASA classification } \\
\hline$\|$ & $26(4.67 \%)$ & $32(3.85 \%)$ & \multirow[t]{3}{*}{0.796} \\
\hline III & $528(93.71 \%)$ & 795 (95.67\%) & \\
\hline IV & $9(1.62 \%)$ & $4(0.48 \%)$ & \\
\hline
\end{tabular}

Data are median (IQR) and patient's number (\%)

Table 2 Laboratory data

\begin{tabular}{|c|c|c|c|}
\hline & Propofol $(n=557)$ & Dexmedetomidine $(n=831)$ & $P$ value \\
\hline \multicolumn{4}{|l|}{ Preoperation } \\
\hline Urea nitrogen (mmol/l) & $3.29(3.05,3.89)$ & $3.47(3.05,3.89)$ & 0.181 \\
\hline Creatinine $(\mu \mathrm{mol} / \mathrm{l})$ & $38(31,48)$ & $38(31,48)$ & 0.862 \\
\hline White blood cells $\left(10^{\mathrm{X9}} / \mathrm{L}\right)$ & $4.08(3.89,4.28)$ & $4.08(3.89,4.29)$ & 0.924 \\
\hline Neutrophiles $\left(10^{X 9} / \mathrm{L}\right.$ & $3.26(3.02,3.89)$ & $3.29(3.02,3.89)$ & 0.318 \\
\hline \multicolumn{4}{|l|}{ Postoperation } \\
\hline Urea nitrogen (24h, mmol/l) & $6.37(6.16,7.07)$ & $6.26(6.14,7.07)$ & 0.003 \\
\hline Creatinine $(24 \mathrm{~h}, \mu \mathrm{mol} / \mathrm{l})$ & $69(61,89)$ & $68(58,89)$ & $<0.001$ \\
\hline White blood cells $\left(72 \mathrm{~h}, 10^{\mathrm{X} 9} / \mathrm{L}\right)$ & $10.06(9.37,10.37)$ & $9.27(9.07,9.97)$ & $<0.001$ \\
\hline Neutrophiles $\left(72 \mathrm{~h}, 10^{\times 9} / \mathrm{L}\right)$ & $6.48(6.14,7.07)$ & $6.26(6.05,7.03)$ & $<0.001$ \\
\hline
\end{tabular}

Data are median (IQR) and patient's number (\%)

with reduction in the ICU mechanical lung ventilation time and is conducive to lung recruitment [14].
DEX has been reported to suppress oxidative stress and inflammatory response in the lung [15] and diminish the severity of acute lung injury produced by remote organ 
Table 3 Postoperative data

\begin{tabular}{|c|c|c|c|}
\hline & Propofol $(n=557)$ & Dexmedetomidine $(n=831)$ & $P$ value \\
\hline All cause 30-day mortality & 12 & 21 & 0.655 \\
\hline New onset arrythmia & $22(3.95 \%)$ & $37(4.45 \%)$ & 0.649 \\
\hline Atrial fibrillation & 12 & 9 & 0.109 \\
\hline Ventricular fibrillation & 10 & 27 & 0.099 \\
\hline Frequent premature ventricular contractions & 0 & 1 & 1.000 \\
\hline Pulmonary complications & $74(13.29 \%)$ & $65(7.82 \%)$ & $<0.01$ \\
\hline Hypoxemia & 23 & 19 & 0.056 \\
\hline Atelectasis & $16(2.87 \%)$ & $11(1.32 \%)$ & 0.048 \\
\hline Pneumonia & 26 & 24 & 0.081 \\
\hline Bronchospasm & 5 & 4 & 0.344 \\
\hline Pleural effusion & $4(0.72 \%)$ & $7(0.84 \%)$ & 1.000 \\
\hline Upper gastrointestinal bleeding & $1(0.18 \%)$ & $2(0.24 \%)$ & 1.000 \\
\hline Surgical bleeding ${ }^{a}$ & $8(1.44 \%)$ & $5(0.60 \%)$ & 0.114 \\
\hline Wound dehiscence or infection & $37(6.64 \%)$ & $21(2.53 \%)$ & $<0.001$ \\
\hline Acute kidney injury & $4(0.72 \%)$ & $6(0.72 \%)$ & 1.000 \\
\hline Stroke & $2(0.36 \%)$ & $3(0.36 \%)$ & 1.000 \\
\hline Coronary artery CTA follow up & $58(10.41 \%)$ & $67(8.06 \%)$ & 0.134 \\
\hline Within three months, Bridge vascular root & 12 & 83 & \\
\hline Within three months, Bridge vascular recanalization rate & 10/12(83.33\%) & 77/83(92.77\%) & 0.586 \\
\hline Within 1 year, Bridge vascular root & 17 & 164 & \\
\hline Within 1 year, Bridge vascular recanalization rate & $14 / 17(82.35 \%)$ & $147 / 164(89.63 \%)$ & 0.613 \\
\hline More than 2 years, Bridge vascular root & 173 & 202 & \\
\hline More than 2 years, Bridge vascular recanalization rate & $147 / 173(84.79 \%)$ & 184/202(91.09\%) & 0.066 \\
\hline Length of stay in hospital, days & $22(17,28)$ & $20(17,24)$ & $<0.001$ \\
\hline Duration of mechanical ventilation, hrs & $21(16,37)$ & $18(13,25)$ & $<0.001$ \\
\hline Length of stay in ICU after surgery, hrs & $59(46,94.5)$ & $51(42,90)$ & 0.001 \\
\hline
\end{tabular}

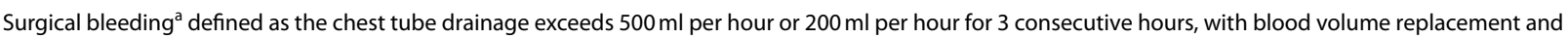
hemodynamic instability

Data are median (IQR), patient's number (\%) or mean \pm SD; CTA: Computed Tomography Angioplasty

ischemia-reperfusion [16]. The pulmonary protective properties may explain the finding of overall improvement in postoperative pulmonary complications. Our finding was in accordance with a recent meta-analysis of nine randomised controlled trials with a total of 1308 patients. DEX use was also associated with lower incidences of pulmonary complications and less mechanical ventilation time [8]. However, unlike our findings, they did not find any significant differences in other postoperative complications, length of ICU or hospital stay, despite previous systemic review and meta-analysis showing the significant reduction [7]. For 30-day mortality, unlike the previous findings [7], we did not find a significant result for DEX; if anything, DEX was trending towards worse 30-day mortality.

When comparing the preoperative factors to match the propofol and DEX group, we found that arrhythmia and alcoholism were significantly more prevalent in the propofol than in the DEX group. However, upon multivariate logistic regression analysis for postoperative pulmonary complications, we did not find these two factors to worsen postoperative pulmonary complications and therefore did not influence the primary outcome in the propofol group.

We found that patients who had DEX could be extubated three hours earlier than patients who received propofol. These findings fit with DEX's well-described properties as a compliant, conscious sedative drug that allows more accessible assessment of conscious level, communication between patient and staff, and better pain control [3]. Our study also found the analgesic properties of DEX, where we showed that the group which received DEX required significantly less opioid than the propofol group.

The perioperative administration of DEX has been shown to reduce surgical stress, inflammatory response and preserve the immune cell function following surgery. DEX could significantly reduce the surge of epinephrine, cortisol, interleukin- 6 and tumour necrosis factor- $\alpha$ following cardiac surgery [6]. DEX may reduce 
Table 4 Factors associated with postoperative pulmonary complications

\begin{tabular}{|c|c|c|c|}
\hline Factors & OR & $95 \% \mathrm{Cl}$ & $P$ value \\
\hline Cardiac arrhythmia & 0.70 & $0.231-$ & 0.548 \\
\hline Alcoholism & 9 & 2.178 & 0.913 \\
\hline Age & 0.97 & $0.620-$ & 0.189 \\
\hline BMI & 5 & 1.532 & 0.561 \\
\hline Time of surgery & 1.01 & $0.993-$ & 0.951 \\
\hline Length of stay in hospital & 5 & 1.037 & 0.399 \\
\hline Duration of mechanical ventilation & 1.020 & $0.953-1.092$ & 0.520 \\
\hline Length of stay in ICU after surgery & 1.000 & $0.992-1.009$ & 0.819 \\
\hline Dex treatment ${ }^{\mathrm{a}}$ & 0.990 & $0.966-1.014$ & 0.002 \\
\hline \multirow[t]{4}{*}{ CPB assistance } & 1.003 & $0.993-1.013$ & $<0.001$ \\
\hline & 0.999 & $0.995-1.004$ & \\
\hline & 0.544 & $0.368-0.802$ & \\
\hline & 0.140 & $0.088-0.223$ & \\
\hline Diabetes & 1.500 & $1.018-2.211$ & 0.040 \\
\hline Wound infection & 3.995 & $2.114-7.551$ & $<0.001$ \\
\hline
\end{tabular}

a Propofol group was the control group; Other variables were negative for the control group

CPB assistance: Extracorporeal circulation used to maintain the stability of circulation, without arresting the heart

postoperative complications such as wound dehiscence or infection, as demonstrated in our study, by alleviating excessive surgical stress and inflammatory response [6]. These, together with its cytoprotective effects, might lead to an overall improvement in clinical outcomes.

To the best of our knowledge, our study is the first study to demonstrate that the use of DEX during cardiac surgery may shorten the surgical time compared to propofol. Other studies that compared the duration of surgery between the use of DEX and the controlled group (any treatment without DEX) have not produced a similar finding [17]. However, although not statistically significant, most of these studies were leaning to favour DEX in reducing cardiac surgery duration [17]. DEX has been shown to produce haemodynamic stability with significant beneficial effects on systolic arterial pressure, mean arterial blood pressure, pulmonary artery mean pressure, heart rate and reducing the incidence of hemodynamic complications $[9,17]$. These proven benefits may render less intra-operative haemodynamic instability; in particular, slowing down heart rate can enhance better-suturing performance by surgeons and hence reduce surgery time; all of which are useful during cardiac surgery and lead to less surgical time. However, this will need further investigation.

Our study did not find that DEX prevented the occurrence of new onset of cardiac arrhythmias in the postoperative period any more than propofol. This finding is in keeping with those from a recent $\mathrm{RCT}$ and observational
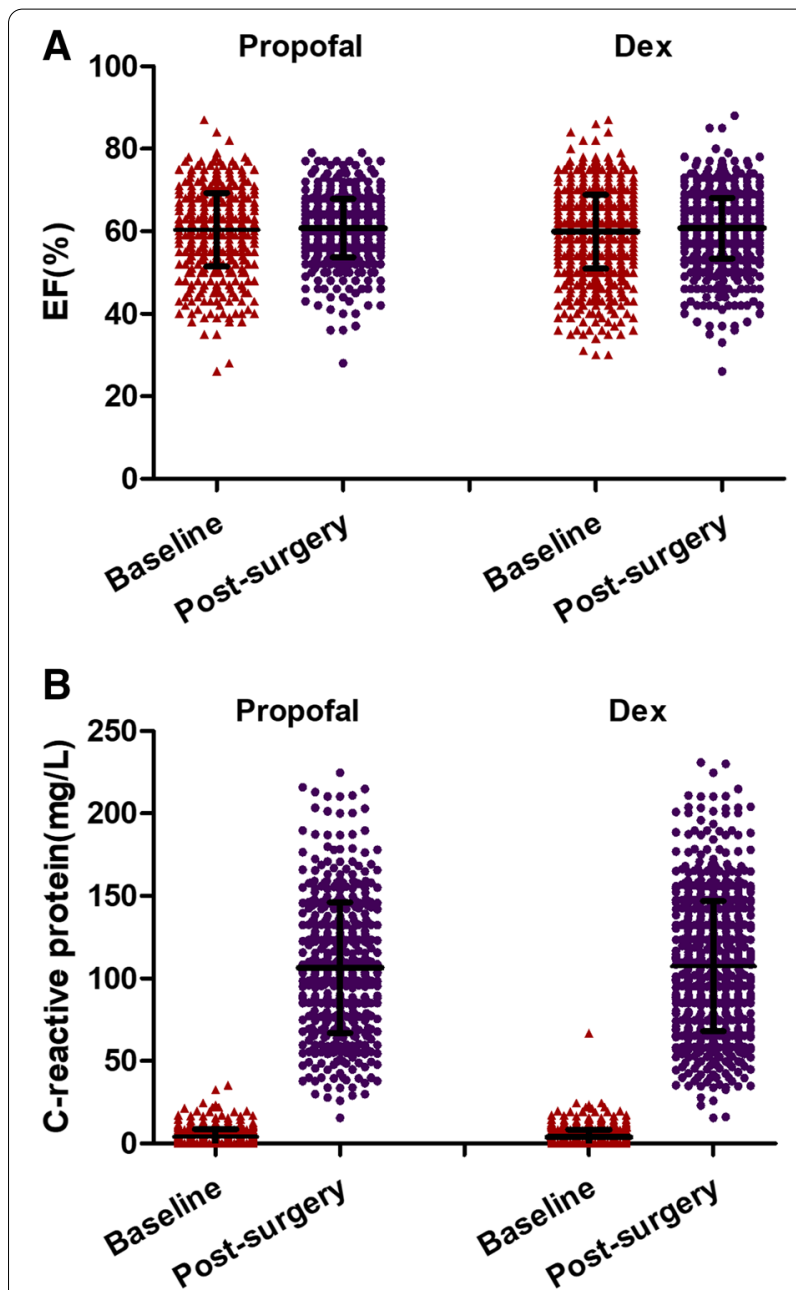

Fig. 2 Cardiac ejection fraction (EF) (A) and C-reactive protein (CRP) (B) data before and after surgery under propofol $(n=557)$ or dexmedetomidine anesthesia $(n=831)$. Data are median (IQR). There was no statistical significance between before and after surgery

study $[18,19]$. Evidence from other studies remains variable; for example, some studies found the incidence of atrial fibrillation was reduced following the administration of DEX [20, 21].

The cytoprotective effects of DEX on multi-organs have been well documented in the brain, lung, and kidney [21-25]. In oxidative stress-induced lung injury, DEX increased alveolar cell survival and proliferation by activating the protective signalling pathways in lung cells and preventing cellular apoptosis [24]. Both the anti-inflammatory and $\alpha_{2}$ adrenergic receptor-dependent mechanisms provide lung protection against acute lung injury [26]. DEX provides renal protection via the anti-inflammatory effects of the parasympathetic system activation in addition to its direct actions on the $\alpha_{2}$-adrenergic receptor [22]. Serine/threonine-protein kinase, a pathway that plays a crucial role in cytoprotective signalling, is 
Table 5 Data during surgery

\begin{tabular}{llll}
\hline & Propofol $(\boldsymbol{n}=\mathbf{5 5 7})$ & Dexmedetomidine $(\boldsymbol{n}=\mathbf{8 3 1})$ & \\
\hline Usage of anesthetics & & \\
Sufentanil, $\mu \mathrm{g}$ & $271(242,300)$ & $267(233,292)$ \\
Propofol, $\mathrm{mg}$ & $1105.49(633-2067)$ & \\
Dexmedetomidine, $\mu \mathrm{g}$ & & $217.06(113-593)$ \\
Methoxamine, $\mathrm{mg}$ & $19(16,21)$ & $13(12,16)$ & 0.001 \\
Time of surgery, min & $280(250,320)$ & $275(240,310)$ & 0.001 \\
Intraoperative infusion of crystal fluid, $\mathrm{ml}$ & $1000(800,1500)$ & $1000(1000,1500)$ & $1000(1000,1500)$ \\
Intraoperative infusion of colloidal solution, $\mathrm{ml}$ & $1000(1000,1500)$ & $1700(1200,2300)$ & 0.005 \\
Intraoperative urine volume, $\mathrm{ml}$ & $1700(1200,2200)$ & $300(200,400)$ & 0.502 \\
Intraoperative infusion of autologous blood, $\mathrm{ml}$ & $300(200,500)$ & $67(8.06 \%)$ & 0.564 \\
cardiopulmonary bypass & $39(7 \%)$ & $42(5.05 \%)$ & 0.164 \\
IABP assistance & $27(4.85 \%)$ &
\end{tabular}

Data are median (IQR) and patient's number (\%). IABP: Intra-aortic balloon pump

activated by DEX, leading to the reduction in the pathological changes following ischaemia-reperfusion injury in the kidneys. DEX also attenuates Toll-like Receptor 4 (TLR4) expression in tubular cells, which leads to decreased tubular epithelial cell death [23]. All these findings above indicate that DEX may improve short/long term surgical (including cardiac surgeries) outcomes.

Our finding that $\mathrm{CPB}$ assistance decreased postoperative pulmonary complications conflicted with previous studies. Multiple inflammatory responses following $\mathrm{CPB}$ use has been described as the major causes of pulmonary damage following on-pump CABG surgery [27]. In several studies comparing on-pump and off-pump CABG, $\mathrm{CPB}$ used was associated with a significant increase in postoperative pulmonary complications such as pneumonia $[28,29]$. Although one study did not find a significant difference in postoperative lung function tests [28]. We used CPB assistance in a specific group of patients with circulatory instability following acute myocardial infarction and heart failure, and therefore our finding cannot be generalized. The correlation between diabetes and postoperative pulmonary complication has also been described as controversial [27]. Although we found that diabetes may worsen postoperative pulmonary complications, another study found no significant difference in pulmonary complications following CABG between patients with or without diabetes [30]. Postoperative factors such as sternotomy infection may negatively affect pulmonary complications [31], as we found.

The strength of this study lies in the inclusion of a large number of patients of a specific type of cardiac CABG surgery, eliminating heterogeneity between different types of cardiac surgery and any potential varied procedural impact on outcomes. However, there are limitations to this study. First, this study is retrospective, which means that there are limitations in interpreting the results for the general patient population or making any concrete conclusions. Second, other postoperative complications were not assessed postoperatively, particularly postoperative delirium, which is prevalent in cardiac surgery. Third, the lung complications between the two groups were marginally different. Lastly, the underlying mechanisms for why DEX reduced postoperative lung complications and enhanced postoperative recovery remain unknown. All warrant further study in the future.

\section{Conclusions}

Our findings suggest that DEX may reduce short term postoperative pulmonary complications, time on mechanical lung ventilation, ICU and hospital stay following CABG surgery compared to propofol. Our work, reported here, may provide a rationale for further prospective clinical studies investigating the benefits of DEX, including other intraoperative outcomes such as the benefit on surgical time or long-term outcomes such as 30 days mortality following CABG surgery.

\section{Abbreviations}

ICU: Intensive care unit; DEX: Dexmedetomidine; CABG: Coronary artery bypass graft; mg: Milligrams; kg: Kilograms; $\mu g$ : micrograms; I/E: Inspire/expire; VT:Tidal volume; ml: millimetres; min: minutes; hr.: hours; CPB: Cardiopulmonary bypass; LOS: Length of stay; ASA: American Society of Anaesthesiology; SD: Standard deviation; IQR: Interquartile range; TLR4: Toll-like Receptor 4; $\mathrm{PaO}_{2} / \mathrm{FiO}_{2}$ : Oxygenation index; $\mathrm{PaO}_{2}$ : Arterial partial pressure of oxygen; $\mathrm{FiO}_{2}$ : Inhaled oxygen concentration; PEEP: Positive end-expiratory pressure.

\section{Acknowledgements}

None.

\section{Authors' contributions}

$J H, B L$ and RW contributed equally to this work. BL, JH, YY: data collection and analyses; JH, XPC, DM: Conceptualization; RW, CPS, JH, DM: Drafting manuscript, review \& editing. All authors read and approved the final manuscript. 


\section{Funding}

This study was supported by the Science and Technology Development Project of Henan Province (192102310128) and the Medical Science and Technology Research Project of Henan Province (2018020904), China.

\section{Availability of data and materials}

The datasets used and/or analysed during the current study are available from the corresponding author on reasonable request.

\section{Declarations}

\section{Ethics approval and consent to participate}

This study was approved by the ethics committee of Luoyang Central Hospital, Zhengzhou University, Henan, China. Because of the retrospective nature of the study, informed consent was waived.

\section{Consent for publication}

Not applicable.

\section{Competing interests}

The authors declare that they have no competing interests.

\section{Author details}

1Department of Anesthesiology, Luoyang Central Hospital Affiliated to Zhengzhou University, Luoyang, Henan, China. ${ }^{2}$ Division of Anaesthetics, Pain Medicine and Intensive Care, Department of Surgery and Cancer, Faculty of Medicine, Imperial College London, Chelsea and Westminster Hospital, London, UK. ${ }^{3}$ Department of cardiovascular surgery, Luoyang Central Hospital Affiliated to Zhengzhou University, Luoyang, Henan, China. ${ }^{4}$ Information Center, Luoyang Central Hospital Affiliated to Zhengzhou University, Luoyang, Henan, China. ${ }^{5}$ Department of Anesthesiology, Wycombe General Hospital, Queen Alexandra Road, High Wycombe, Buckinghamshire HP11 2TT, UK.

Received: 5 April 2021 Accepted: 27 January 2022

Published online: 19 February 2022

\section{References}

1. LaPar DJ, Gillen JR, Crosby IK, et al. Predictors of operative mortality in cardiac surgical patients with prolonged intensive care unit duration. J Am Coll Surg. 2013;216(6):1116-23. https://doi.org/10.1016/j.jamcollsurg. 2013.02.028.

2. Fernandez-Zamora MD, Gordillo-Brenes A, Banderas-Bravo E, et al. Prolonged Mechanical Ventilation as a Predictor of Mortality After Cardiac Surgery. Respir Care. 2018;63(5):550-7. https://doi.org/10.4187/respcare. 04915.

3. Rahman WR, Rhodes A, Grounds RM. The Role of Dexmedetomidine in Intensive Care. In: Vincent JL, editor. Yearbook of Intensive Care and Emergency Medicine. Yearbook of Intensive Care and Emergency Medicine, vol 2009. Berlin, Heidelberg: Springer; 2009. https://doi.org/10.1007/ 978-3-540-92276-6_81.

4. Lee $\mathrm{SH}$, Kim N, Lee CY, et al. Effects of dexmedetomidine on oxygenation and lung mechanics in patients with moderate chronic obstructive pulmonary disease undergoing lung cancer surgery: a randomised double-blinded trial. Eur J Anaesthesiol. 2016;33:275-82.

5. Huang S, Zhang J, Zhang $X$, et al. Can Dexmedetomidine improve arterial oxygenation and intrapulmonary shunt during one-lung ventilation in adults undergoing thoracic surgery? A meta-analysis of randomized, placebo-controlled trials. Chin Med J. 2017;130:1707-14.

6. Wang K, Wu MG, Xu J, et al. Effects of dexmedetomidine on perioperative stress, inflammation, and immune function: systematic review and meta-analysis. Br J Anaesth. 2019;123:777-94. https://doi.org/10.1016/j. bja.2019.07.027.

7. Peng K, Ji FH, Liu HY, et al. Effects of Perioperative Dexmedetomidine on Postoperative Mortality and Morbidity: A Systematic Review and Metaanalysis. Clin Ther. 2019;41(1):138-54. e4. https://doi.org/10.1016/j.clint hera.2018.10.022.

8. Peng K, Li D, Applegate RL 2nd, et al. Effect of Dexmedetomidine on Cardiac Surgery-Associated Acute Kidney Injury: A Meta-Analysis With
Trial Sequential Analysis of Randomized Controlled Trials. J Cardiothorac Vasc Anesth. 2020;34(3):603-13. https://doi.org/10.1053/j.jvca.2019.09. 011 Epub 2019 Sep 16. PMID: 31587928.

9. Sheikh TA, Dar BA, Akhter N, et al. A Comparative Study Evaluating Effects of Intravenous Sedation by Dexmedetomidine and Propofol on Patient Hemodynamics and Postoperative Outcomes in Cardiac Surgery. Anesth Essays Res. 2018;12(2):555-60. https://doi.org/10.4103/aer.AER_46_18 PMID: 29962634; PMCID: PMC6020583.

10. Kabukçu HK, Sahin N, Temel Y, et al. Hemodynamics in coronary artery bypass surgery: Effects of intraoperative dexmedetomidine administration. Anaesthesist. 2011;60:427-31.

11. Kunisawa T, Ueno M, Kurosawa A, et al. Dexmedetomidine can stabilize hemodynamics and spare anesthetics before cardiopulmonary bypass. J Anesth. 2011;25:818-22.

12. Geng J, Qian J, Cheng H, et al. The influence of perioperative dexmedetomidine on patients undergoing cardiac surgery: A meta-analysis. PLoS One. 2016;11:e0152829.

13. Von Elm E, Altman DG, Egger M, et al. The Strengthening the Reporting of Observational Studies in Epidemiology (STROBE) statement: guidelines for reporting observational studies. J Clin Epidemiol. 2008;61:344-9.

14. Liu Y, Zhu X, Zhou D, et al. Dexmedetomidine for prevention of postoperative pulmonary complications in patients after oral and maxillofacial surgery with fibular free flap reconstruction: a prospective, double-blind, randomized, placebo-controlled trial. BMC Anesthesiol. 2020;20(1):127. https://doi.org/10.1186/s12871-020-01045.

15. Gao S, Wang Y, Zhao J, et al. Effects of dexmedetomidine pretreatment on heme oxygenase-1 expression and oxidative stress during one-lung ventilation. Int. J Clin Exp Pathol. 2015;8(3):3144-9 PMCID: PMC4440140.

16. Chi X, Wei X, Gao W, et al. Dexmedetomidine ameliorates acute lung injury following orthotopic autologous liver transplantation in rats probably by inhibiting Toll-like receptor 4-nuclear factor kappa B signalling. J Transl Med. 2015;13:190. PMCID: PMC4467671. https://doi.org/10.1186/ s12967-015-0554-5.

17. Wang G, Niu J, Li Z, et al. The efficacy and safety of dexmedetomidine in cardiac surgery patients: A systematic review and meta-analysis. PLoS One. 2018;13(9):e0202620. Published 2018 Sep 19. https://doi.org/10. 1371/journal.pone.0202620.

18. Zientara A, Mariotti S, Matter-Ensner S, et al. Fast-Track Management in Off-Pump Coronary Artery Bypass Grafting: Dexmedetomidine Provides Rapid Extubation and Effective Pain Modulation. Thorac Cardiovasc Surg. 2019;67(6):450-7. https://doi.org/10.1055/s-0038-1668602.

19. Soltani $G$, Jahanbakhsh S, Tashnizi MA, et al. Effects of dexmedetomidine on heart arrhythmia prevention in off-pump coronary artery bypass surgery: A randomized clinical trial. Electron Physician. 2017;9(10):5578-87. https://doi.org/10.19082/5578.

20. Liu Y, Zhang L, Wang S, et al. Dexmedetomidine Reduces Atrial Fibrillation After Adult Cardiac Surgery: A Meta-Analysis of Randomized Controlled Trials. Am J Cardiovasc Drugs. 2020;20(3):271-81.

21. Turan A, Duncan A, Leung $S$, et al. Dexmedetomidine for reduction of atrial fibrillation and delirium after cardiac surgery (DECADE): a randomised placebo-controlled trial. Lancet. 2020;396(10245):177-85. https://doi.org/10.1016/S0140-6736(20)30631-0.

22. Ma J, Chen Q, Li J, et al. Dexmedetomidine-Mediated Prevention of Renal Ischemia-Reperfusion Injury Depends in Part on Cholinergic Anti-Inflammatory Mechanisms. Anesth Analg. 2020;130(4):1054-62. https://doi.org/ 10.1213/ANE.0000000000003820 PMID: 30346356.

23. Gu J, Sun $P$, Zhao H, et al. Dexmedetomidine provides renoprotection against ischemia-reperfusion injury in mice. Crit Care. 2011;15:R153. https://doi.org/10.1186/cc10283.

24. Cui J, Zhao H, Wang C, et al. Dexmedetomidine attenuates oxidative stress induced lung alveolar epithelial cell apoptosis in vitro. Oxid Med Cell Longev. 2015;2015:358396. https://doi.org/10.1155/2015/358396 Epub 2015 Mar 8. PMID: 25838866; PMCID: PMC4369905.

25. Rajakumaraswamy N, Ma D, Hossain M, et al. Neuroprotective interaction produced by xenon and dexmedetomidine on in vitro and in vivo neuronal injury models. Neurosci Lett. 2006;409(2):128-33. https://doi.org/10. 1016/j.neulet.2006.09.020 Epub 2006 Oct 18. PMID: 17052852.

26. Gu J, Chen J, Xia P, et al. Dexmedetomidine attenuates remote lung injury induced by renal ischemia-reperfusion in mice. Acta Anaesthesiol Scand. 2011;55(10):1272-8. https://doi.org/10.1111/j.1399-6576.2011.02526.x Epub 2011 Sep 26. PMID: 22092133. 
27. Mali S, Haghaninejad H. Pulmonary complications following cardiac surgery. Arch Med Sci Atheroscler Dis. 2019;4:e280-5. https://doi.org/10. 5114/amsad.2019.91432 PMID: 32368683; PMCID: PMC7191937.

28. Staton GW, Williams WH, Mahoney EM, et al. Pulmonary outcomes of offpump vs on-pump coronary artery bypass surgery in a randomized trial. Chest. 2005;127:892-901.

29. Mack MJ, Pfister A, Bachand D, et al. Comparison of coronary bypass surgery with and without cardiopulmonary bypass in patients with multivessel disease. J Thorac Cardiovasc Surg. 2004;127:167-73.

30. Ji Q, Mei Y, Wang X, Feng J, Cai J, Ding W. Risk factors for pulmonary complications following cardiac surgery with cardiopulmonary bypass. Int J Med Sci. 2013;10:1578-83.

31. Dubert M, Pourbaix A, Alkhoder S, et al. Sternal wound infection after cardiac surgery: management and out- come. PLoS One. 2015;10:e0139122.

\section{Publisher's Note}

Springer Nature remains neutral with regard to jurisdictional claims in published maps and institutional affiliations.

- fast, convenient online submission

- thorough peer review by experienced researchers in your field

- rapid publication on acceptance

- support for research data, including large and complex data types

- gold Open Access which fosters wider collaboration and increased citations

- maximum visibility for your research: over $100 \mathrm{M}$ website views per year

At BMC, research is always in progress.

Learn more biomedcentral.com/submissions 